DOT/FAA/AM-01/8

Office of Aviation Medicine

Washington, D.C. 20591

\section{Data-Linked Pilot Reply Time On Controller Workload and Communication in a Simulated Terminal Option}

\author{
O. Veronika Prinzo
}

Civil Aeromedical Institute

Federal Aviation Administration

Oklahoma City, Oklahoma 73125

May 2001

Final Report

This document is available to the public through the National Technical Information Service, Springfield, Virginia 22161.

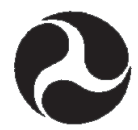

U.S. Department of Transportation Federal Aviation Administration 


\section{$N O T I C E$}

This document is disseminated under the sponsorship of the U.S. Department of Transportation in the interest of information exchange. The United States Government assumes no liability for the contents thereof. 
Technical Report Doc umentation Page

\begin{tabular}{|c|c|c|c|c|}
\hline $\begin{array}{l}\text { 1. Report No. } \\
\text { DOT/FAA/AM-01/8 }\end{array}$ & \multicolumn{2}{|c|}{ 2. Government Accession No. } & \multicolumn{2}{|c|}{ 3. Recipient's Catalog No. } \\
\hline \multicolumn{3}{|l|}{ 4. Title and Subtitle } & \multicolumn{2}{|l|}{ 5. Report Date } \\
\hline \multirow{2}{*}{\multicolumn{3}{|c|}{$\begin{array}{l}\text { Data-Linked Pilot Reply Time on Controller Workload and } \\
\text { Communication in a Simulated Terminal Option }\end{array}$}} & \multicolumn{2}{|l|}{ May 2001} \\
\hline & & & \multicolumn{2}{|c|}{ 6. Performing Organization Code } \\
\hline \multicolumn{3}{|l|}{$\begin{array}{l}\text { 7. Author(s) } \\
\text { Prinzo, O.V. }\end{array}$} & \multicolumn{2}{|c|}{ 8. Performing Organization Report No. } \\
\hline \multirow{2}{*}{\multicolumn{3}{|c|}{$\begin{array}{l}\text { FAA Civil Aeromedical Institute } \\
\text { P.O. Box } 25082 \\
\text { Oklahoma City, OK } 73125\end{array}$}} & \multicolumn{2}{|c|}{ 10. Work Unit No. (TRAIS) } \\
\hline & & & \multicolumn{2}{|c|}{ 11. Contract or Grant No. } \\
\hline & \multicolumn{2}{|c|}{ 13. Type of Report and Period Covered } \\
\hline \multirow{2}{*}{\multicolumn{3}{|c|}{$\begin{array}{l}\text { Office of Aviation Medicine } \\
\text { Federal Aviation Administration } \\
800 \text { Independence Ave., S.W. } \\
\text { Washington, D.C. } 20591\end{array}$}} & & \\
\hline & & & 14. Sponsoring & \\
\hline \multicolumn{5}{|c|}{ This work was performed under Task AM-B-98-HRR-516. } \\
\hline \multicolumn{5}{|c|}{ 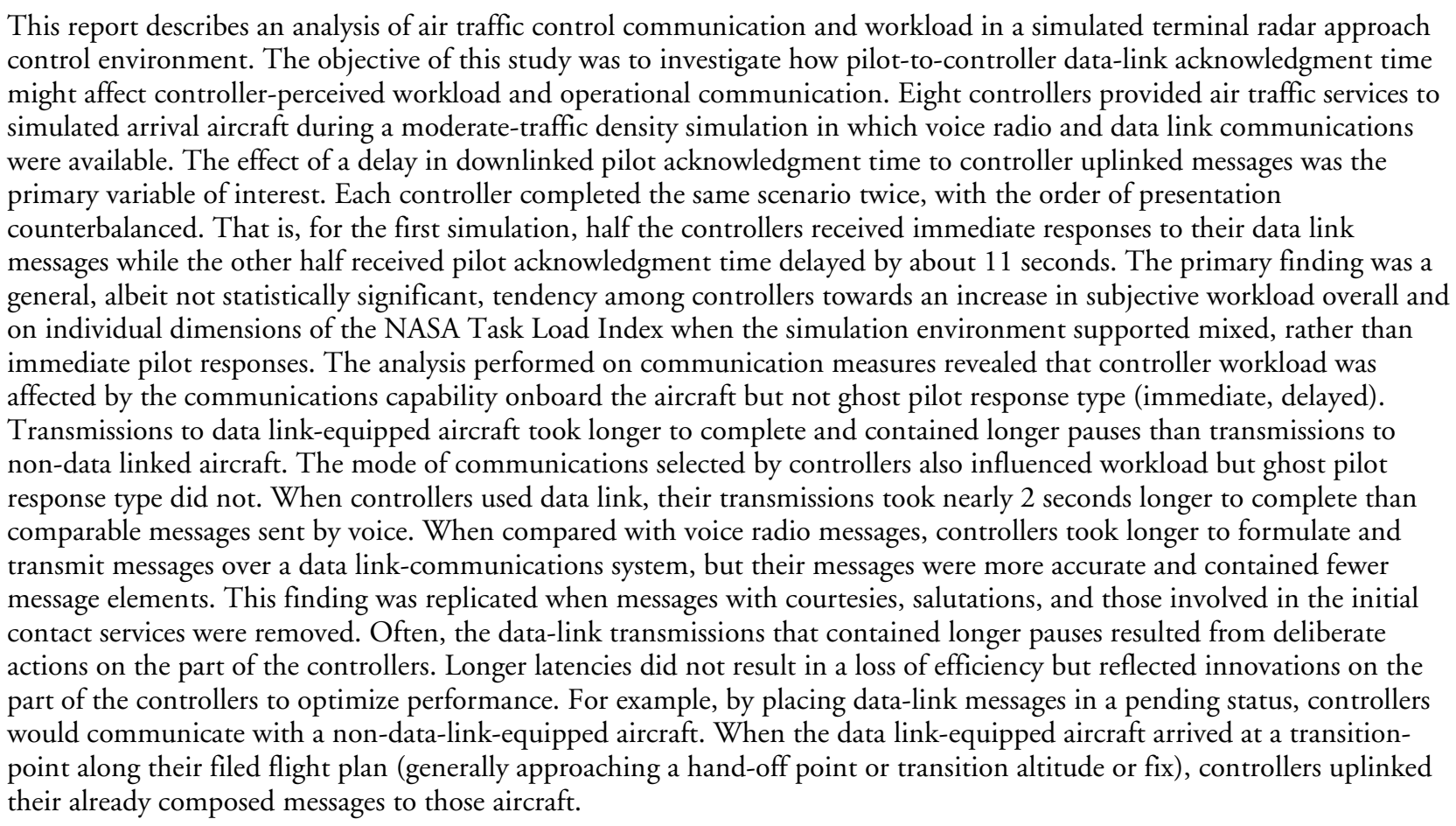 } \\
\hline \multicolumn{2}{|c|}{$\begin{array}{l}\text { 17. Key Words } \\
\text { Air Traffic Control Communication, Data Link }\end{array}$} & \multicolumn{3}{|c|}{ 18. Distribution Statement } \\
\hline $\begin{array}{l}\text { 19. Security Classif. (of this report) } \\
\text { Unclassified }\end{array}$ & $\begin{array}{r}\text { 20. Security Classif. } \\
\text { U }\end{array}$ & & $\begin{array}{l}\text { 21. No. of Pages } \\
21\end{array}$ & 22. Price \\
\hline
\end{tabular}





\section{ACKNOWLEDGMENTS}

I thank the air traffic controllers, supervisors, managers, and staff from the Southwest Region for their help and participation in this study. Also, greatly appreciated was the assistance provided by Mr. Al Hendrix (subject matter expert), the OMNI Corporation for providing the air traffic control and pseudo pilots for this study, and Abacus Technologies for software and technical support. Ms. Sandy Dooty, Mr. Scott Hughes, and Mr. James Robinson (subject matter expert) receive a special acknowledgment for the many tedious hours of effort devoted to transcribing, coding messages into speech acts, and preparing the databases for analysis. 



\section{TABLE OF CONTENTS}

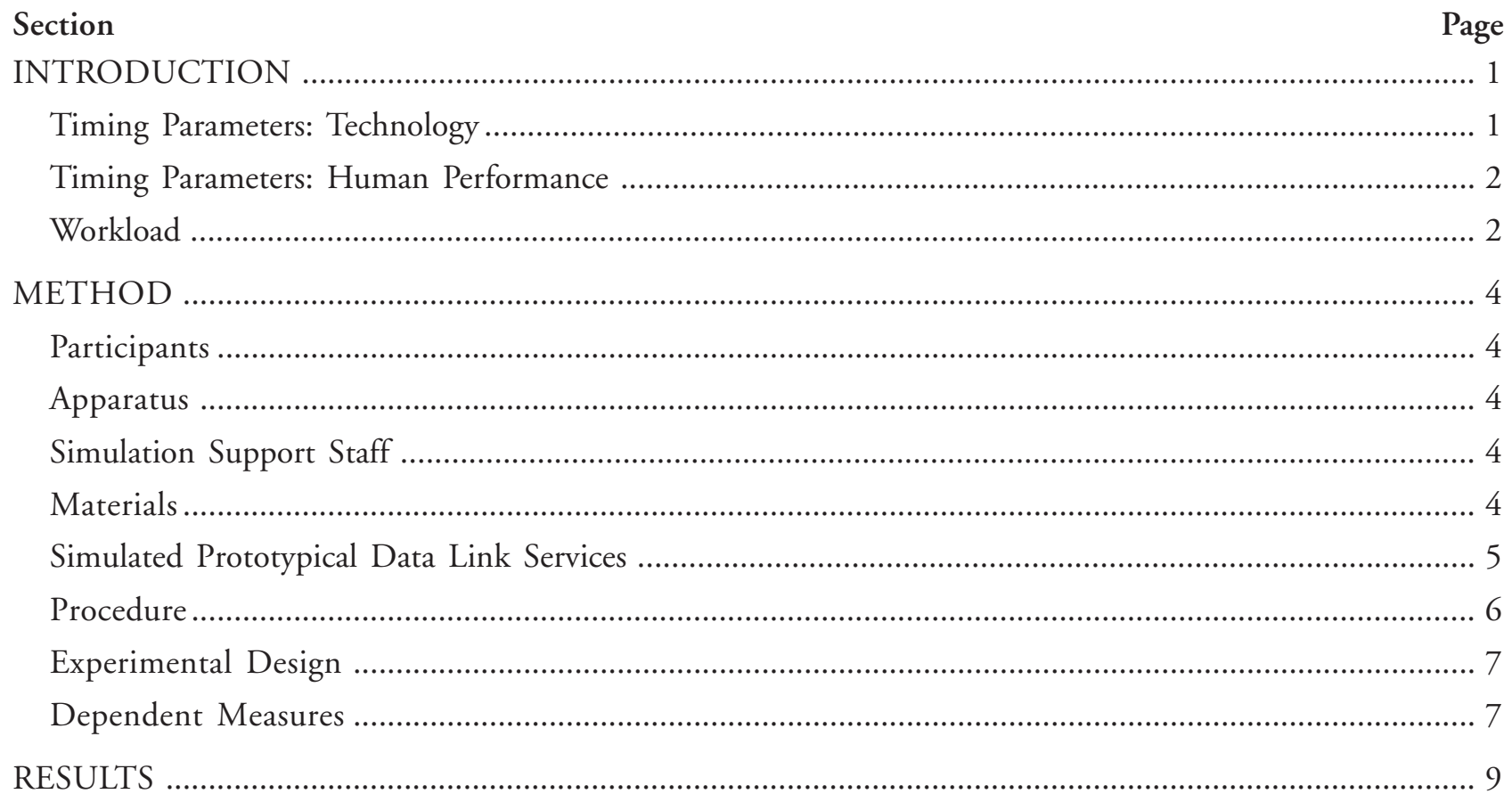

The Relationship Between the Temporal Characteristics of the Simulation Environment and Subjective Workload

The Relationship Between the Temporal Characteristics of the Simulation Environment, Objective Workload and Communication Performance ............................................................................... 9

The Relationship Between the Temporal Characteristics of Downlinked Ghost Pilot Responses and Objective Measures of Initial Contact and Transfer of Control Performance .................................. 11

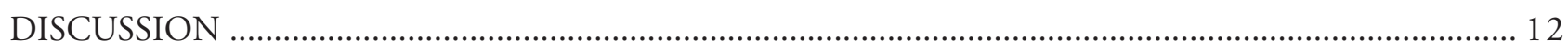

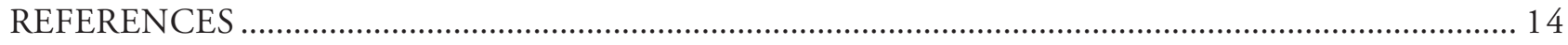





\section{Data-Linked Pilot Reply Time on Controller Workload and Communication in a Simulated Terminal Option}

"Men have become the tools of their tools."

—Henry David Thoreau (1817-1862)

\section{INTRODUCTION}

The Aeronautical Data Link System (ADLS) is being developed as part of the Federal Aviation Administration's (FAA, 1995, 1997) modernization plan to improve safety, reduce delays, and increase the efficiency of human and system resource utilization. As part of this effort, Controller/Pilot Data Link Communication (CPDLC) is being developed to re-direct routine air traffic services provided by an overly taxed voice radio communications system. CPDLC represents the first phase of the transition from the analog voice system to an International Civil Aviation Organization (ICAO) compliant system $^{1}$. Initially, CPDLC en route applications will support limited services. However, as CPDLC matures, additional services will be added and it may expand to include terminal applications. Ultimately, CPDLC services will provide controllers with the capability to initiate a data link uplink message, using pre-defined message sets, to service eligible aircraft and receive data link messages (FAA, 1998a, 1998b).

\section{Timing Parameters: Technology}

The arrival of CPDLC messages to the intended receiver is dependent, in part, upon the speed of endto-end information transfer among ADLS components. End-to-end transfer delay is defined as "the period elapsed from the time at which the originating user initiates the triggering event until the time the transmitted information is available for display to the intended recipient" (FAA, 1997, p. 39). Based on this definition, the estimated end-to-end transfer delay times and performance limits, as derived from the initial requirements for CPDLC in the terminal domain, are presented in Table 1 (FAA, 1997).

A few studies of data link flight deck simulation have reported throughput delays (this could include the processing speed of a device in Mhz, the data transfer rate, and other delays due to the limitations of the technology). For instance, Waller and Lohr (1989) incorporated a 4.1s end-to-end transfer delay, and Knox and Scanlon (1991) included a 1.5s delay (3s round-trip delay). Likewise, delays of 4-6s (mean $=5 \mathrm{~s}$ ) have been used by the Data Link Benefits Study Team (DLBST) to examine terminal data link (1996) and delays of 6 s multiples on downlink for an en route Mode S radar system (1995).

\section{Timing Parameters: Human Performance}

Total transaction times will inevitably involve human delays. Airborne systems, for example, include a 2 s delay before a pilot could reply to an ATC transmission (SAE ARP4791 Revision A, 7.7.11). This parameter allows the non-flying pilot sufficient time to read 10 words from a display with an average silent reading rate of about 5 words per s (Stricht $\&$ Hall, 1984). Therefore, under optimal conditions, a pilot flying in terminal approach control airspace could receive a message $5 \mathrm{~s}$ after it was sent, read a 10-

TABLE 1. CPDLC End-to-End Transfer Delay Performance Presented by Domains.

\begin{tabular}{lccc}
\hline Domain & $\begin{array}{l}\text { Mean End-to-End } \\
\text { Transfer Delay }\end{array}$ & $\begin{array}{l}\text { 95\% End-to-End } \\
\text { Transfer Delay }\end{array}$ & $\begin{array}{l}\text { 99.996\% End-to-End } \\
\text { Transfer Delay }\end{array}$ \\
\hline Terminal & $5 \mathrm{sec}$ & $8 \mathrm{sec}$ & $12.5 \mathrm{sec}$ \\
En Route & $10 \mathrm{sec}$ & $15 \mathrm{sec}$ & $22 \mathrm{sec}$ \\
\hline
\end{tabular}

${ }^{1}$ The system shall comply with ICAO Standards and Recommended Practices (SARPs), Aeronautical Telecommunications, Annex 10 to the Convention on International Civil Aviation, Volume III, Part I, Digital Communication Systems, Chapter 3, Aeronautical Telecommunication Network (ATN). 
word message in $2 s$ and be ready to transmit a reply. From the moment the message leaves the ground until the pilot executes a response, $7 \mathrm{~s}$ lapses.

On the airborne side, total transaction time has been defined as "message receipt to pilot acknowledgement in data link" (Logsdon, et al., 1995, p. 327). It includes time for the pilot to access the message, read it, and acknowledge it (McGann, et al., 1998). However, in some instances, "total transaction time" and "response time" appear to be interchangeable. Waller and Lohr (1989), for example, defined response time as "the time between the first alerting signal indicating the arrival of a new message in the cockpit and the copilot depressing the 'ENT' key to downlink a roger or unable response" (p. 8). In contrast, Talotta et al (1990) decomposed total transaction time into Response Latency (RL) and Wilco/ UNABLE Response Time (WUT). RL was defined as "the interval begins when 'Touch for ATC Message' appears on the display and ends when the pilot touches the prompt 'Touch for ATC Message'." The WUT was defined as "The interval begins with the appearance of the ATC Instruction on the display screen and ends with the touch of WILCO or UNABLE” (p. 35).

On the ground side, the results of the 1996 Data Link Benefits Study Team (DLBST) study, performed at the FAA's William J. Hughes Technical Center for terminal approach control data link, revealed controller transaction times that ranged from $8 \mathrm{~s}$ to more than 200s. In that study, total transaction time was defined as "the period of elapsed time from the controller's input to send the message to the appearance of a downlinked response on the controller's display" (p.79). Furthermore, it "includes the technical system delays associated with uplink and downlink and the time required by the pilots to detect, process, and respond to the message" (p. 77). A closer examination of the frequency distribution of end-toend transfer delay times revealed that about $74 \%$ of the transactions were completed between $10.1 \mathrm{~s}$ and 16.0s. It was further noted that completing transactions in less than 10 s occurred for fewer than 250 of the 9,036 messages.

In a simulation study performed by Knox and Scanlon (1991) "total message transaction time" was defined as "the time from when a message is sent from the ground until the ground receives the pilot's roger or unable response" (p. 9). This definition is comparable to the one provided in the DLBST Report
(1996). That is, total transaction time represents the entire time span a controller would need to maintain awareness of the status of a communication.

Clearly, technology- and human-based delays can influence the efficacy of air-ground operational communication performance required for ATS communications supporting specific services, operations, or procedures within defined homogeneous airspace. For example, the Kerns (1991) review of the data link literature indicated that, on the average, data link total transaction times were twice as long as for voice. Likewise, en route total transaction times varied from 19-21 seconds for data link and 8-10 seconds for voice (Waller \& Lohr, 1989; Talotta et al., 1990). These added delays resulted, in part, from pilots auto-loading information into their navigation computer Control Display Unit (CDU) before down linking an acknowledgment (Waller \& Lohr, 1989).

\section{Workload}

Kerns' (1991) review of the data link literature states, "Virtually all of the studies report no significant effect on pilot or controller workload as a result of using the data link" (pp191). In a later statement, Kerns indicates that, with respect to pilots, "... the research results do document a redistribution of workload across the human's information-processing resources: Visual and manual workload increase whereas auditory and speech workload decrease " (Grouce \& Boucek, 1987). Likewise, for controllers, Talotta et al. (1990) reported a reduced speech workload and an increased manual workload when data link was used.

These outcomes suggest that the redistribution of workload across input and response domains was insufficient to influence overall workload. To address this peculiarity, Prinzo (1998) conducted a simulation study. Following the completion of heavy and light traffic simulations using voice radio only or a combination of voice radio and a data link, controllers provided subjective ratings of workload, using the NASA Task Load Index (TLX) (Hart \& Staveland, 1988). An analysis was performed on the controllers' subjective ratings along 6-dimensions of workload and on a separate overall rating. In addition to their ratings revealing a greater perceived overall workload among controllers when providing approach control services in a mixed compared with a voice only environment, their ratings revealed a perceived increase on several of the individual dimensions. 
For the individual ratings, controllers' ratings were significantly higher on the temporal and frustration dimensions and approached significance on physical demands. It may be that the perceived alterations in workload resulted from controllers switching between voice radio and data link in a mixed-modality environment, using a communications system that was slower than voice radio, or both. Consequently, their subjective ratings on the physical demand dimension may have increased as keyboard entries multiplied. Likewise, their ratings on the temporal demand dimension could have resulted from changes in the temporal component of the communications system (i.e., voice radio is virtually instantaneous, whereas data link is not). These findings agree with the perceptions reported by Auckland Oceanic controllers who estimated about a $40 \%$ increase in workload with CPDLC, without a corresponding increase in traffic (Ruitenbuerg 1998).

It is also possible that an environment supporting both voice radio and data link unknowingly adds a modality-monitoring task to the controller's cognitive workload. This may inadvertently increase perceived ratings of workload. As shown in the upper portion of Figure 1, in a unimodal communication environment, controllers easily monitor their communication transactions with pilots and may hypo- thetically set an internal reply timer. If, after some number of seconds, a reply is not received, the controller might verbally ask the pilot if the message was received. The lower portion shows that, in a dualmode environment, controllers might set one implicit internal timer for voice radio (faster) and another for data link (slower) and develop a strategy to monitor the status of each.

In a dual-mode environment, controllers could create one internal timer based on a single mode, but it could create problems. For example, using voice radio as the default could add to controller workload by increasing the number of queried data link transmissions (not letting the data link total transaction time lapse before re-sending the message). Using data link as the default could create delays or untimely events for aircraft equipped for voice only communications. Consequently, inclusion of a second communications system into air traffic control operational communications could alter communication performance and perceived workload.

Just as the controllers who participated in the Prinzo study (1998) reported elevated subjective workload, so did the assistant controllers who participated in DLBST Experiment 3 (1996). In that DLBST experiment, the assistant controllers sent data link messages to the aircraft, as did the controllers in the

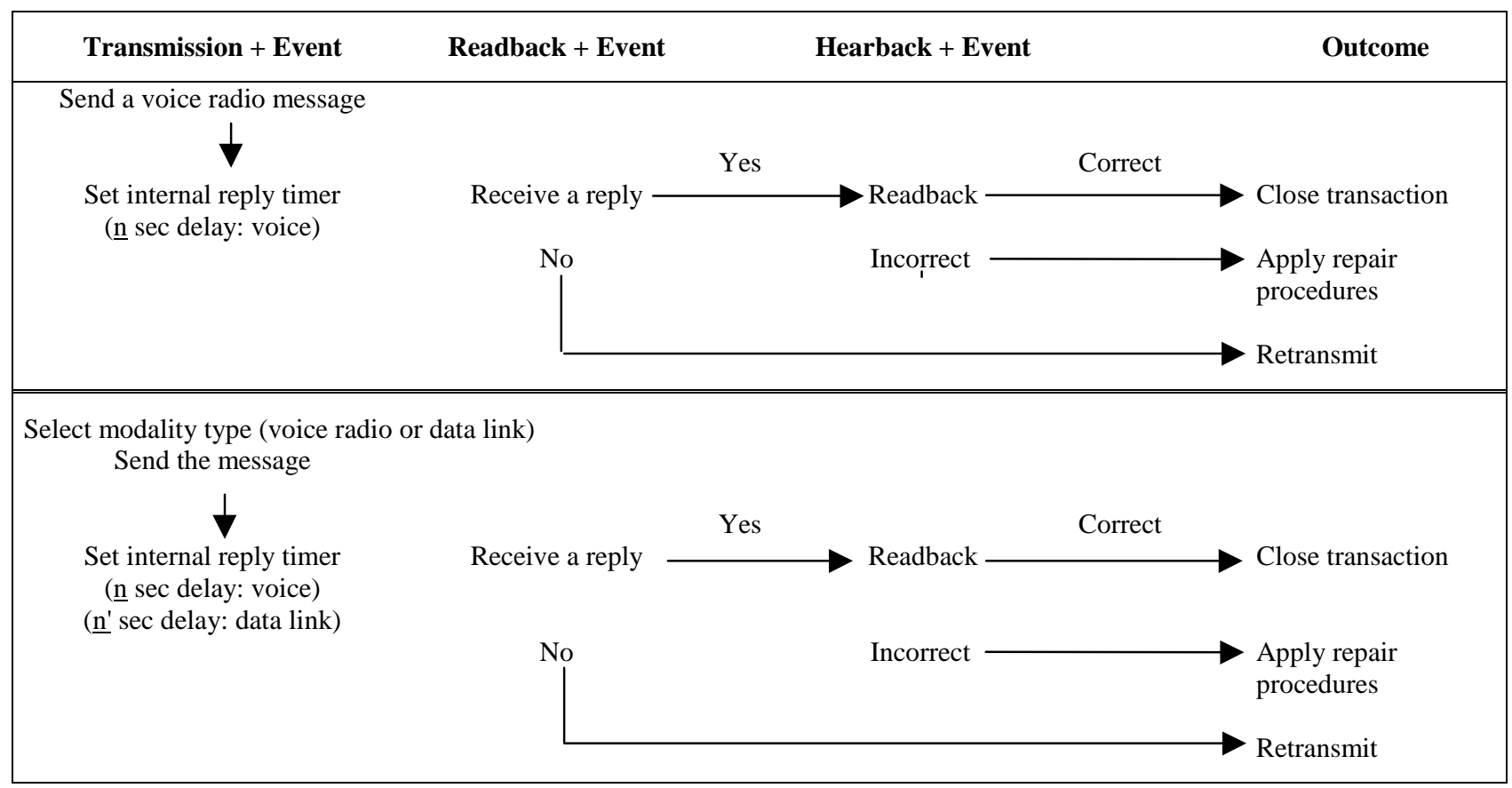

Figure 1. Hypothetical cognitive workload for voice and data link messages. 
Prinzo study. In both simulation studies, controllers provided air traffic services during complex traffic situations (a mix of aircraft arriving at the major and satellite airports). The DLBST concluded that providing air traffic services during highly variable traffic situations (e.g., many different airport destinations, an assortment of aircraft types and performance characteristics, multiple arrival/departure routes) can produce perceptions of greater workload when working with a new set of communications procedures/tools. It was unclear whether the changes in workload and communication performance were attributable to the inherent temporal delays associated with data link transmissions, providing air traffic services in a dual mode environment, or both.

Bower and Clapper (1989) pointed out that people generally tend to pause longer while speaking, especially when heavily involved in planning the next portion of their utterance (pp 281). This observation also was noted by Prinzo, Lieberman, and Pickett (1998) in one simulation study where $82 \%$ of the controllers produced longer intra-sentential pauses for light rather than heavy traffic simulations. Prinzo et al. (1998) suggested that pause duration could reflect differences in information processing demands among controllers. That is, during a lighter workload situation, controllers seemed to use a more flexible, cognitive approach towards traffic management. In effect, the lack of a traffic demand provided them with more time to strategize and vector aircraft. Then, as traffic increased, they seemed to switch to a more automatic and repetitive approach towards maneuvering traffic through their airspace. Thus, hesitation pauses in the context of air traffic control might reflect cognitive demands related to workload. That is, reductions in workload could be reflected by the presence of longer intra-sentential pauses, indicative of more deliberate thought.

The purpose of this simulation study was to disentangle the effects of delay from those due to the communication environment on controller workload. To accomplish this, temporal variations (all immediate responses or mixed) and ghost pilot response type (voice immediate, data link immediate or delayed by approximately 11 s) were manipulated. Their independent and combined effect on controller workload, communication performance, and the performance of initial contact and transfer of control subtasks were examined.

\section{METHOD}

\section{Participants}

Eight full-performance level air traffic control specialists from a level 5 TRACON facility participated in the study. Collectively, they had 14.19 mean years of terminal experience $(S D=5.9)$, with 9.1 mean years $(\mathrm{SD}=7.0)$ at the full-performance level.

\section{Apparatus}

The CAMI TRACON PC-based simulation laboratory includes 2 file servers, 2 controller workstations, 2 ghost pilot workstations, and 1 remote position workstation. Airspace and radar data were presented on 21-inch monitors. The laboratory is designed to provide full audio and video recording capability. A detailed description can be found in Prinzo (1998).

\section{Simulation Support Staff}

The simulation support staff consisted of 2 ghost pilots, 2 retired controllers serving as subject matter experts (SMEs), and a software technician. The certified ghost pilots, formally trained and instructed in ATC communications by a vendor at the FAA Academy in Oklahoma City, also provide support services at the Academy. One SME reviewed and modified the scenarios, developed briefing materials, trained the ghost pilots on the TRACON system and scenarios, and provided them with on-line instruction during each simulation. The other SME was the receiving controller during simulations. The software technician developed front-end applications for the TRACON software to reduce the amount of time and level of effort required for database construction and scenario development.

\section{Materials}

Scenario Development. The TRACON facility's "1997 Game Plan," an internal document, was used to select the time intervals for simulation. It provides historical information pertaining to arrival rushes by direction of arrival into the TRACON airspace. The TRACON facility also provided computer data that contained actual flight plans for a 24-hour (hr) time interval. The flight plan data were reformatted and one 35-minute ( $\mathrm{min}$ ) time interval was selected for simulation. The flight plan data also were used to develop one 15 -min practice scenario to instruct and train participants on the use of the TRACON simulator. 
TABLE 2. Distribution of Arrivals Presented by Aircraft Type and Time Interval in the Scenario

\begin{tabular}{ccccc}
\hline \multirow{2}{*}{$\begin{array}{c}\text { Time Interval } \\
\text { (in Minutes) }\end{array}$} & \multicolumn{4}{c}{ Arrival Aircraft } \\
\cline { 2 - 5 } & Props & AAL (MD80) & Other Jets & Total \\
\hline $00-09$ & 0 & 6 & 6 & $\mathbf{1 2}$ \\
$10-19$ & 2 & 7 & 2 & $\mathbf{1 1}$ \\
$20-29$ & 0 & 6 & 3 & $\mathbf{9}$ \\
$30-40$ & 0 & 3 & 2 & $\mathbf{5}$ \\
Total & $\mathbf{2}$ & $\mathbf{2 2}$ & $\mathbf{1 3}$ & $\mathbf{3 7}$ \\
\hline
\end{tabular}

As shown in Table 2, the distribution of aircraft approaching the sector during each 10-min time interval was moderate. Table 2 also shows that approximately $60 \%$ of the arrival aircraft were from American Airlines' (AAL) fleet of MD80s, and all of them were data link equipped.

The following constraint was imposed. Although all of the airplanes in each of the scenarios were voice radio equipped, only AAL's MD80 aircraft were data link equipped. The Feeder East arrival aircraft appeared approximately 5 miles (mi) from the Northeast and Southeast vortac. All arrival aircraft were on a north flow. The last arrival appeared approximately $35 \mathrm{~min}$ into the simulation. The simulation was stopped once the last MD80 aircraft was handed-off to, and accepted by, the receiving controller staffing the Final sector. The fidelity and realism of the scenario were evaluated by staff from the TRACON facility to ensure that it was representative of day to day traffic operations for the position.

NASA Task Load Index. Hart and Staveland (1988) developed the NASA Task Load Index (TLX). It is a widely used and accepted multi-dimensional subjective rating procedure and is an index of perceived workload. They conceptualized workload as a construct that involves 6 dimensions: Mental Demands, Physical Demands, Temporal Demands, Performance, Effort, and Frustration. Five of the scales are anchored with "low" (0) on the left and "high" (100) on the right. The Performance scale is anchored by "good" (100) on the left of the dimension and "poor" (0) on the right.
Simulated Prototypical Data Link Services

Only the control instructions (CI), terminal information (TI), and transfer of communication (TOC) data link services were simulated. The instructions on how these services were executed are presented below. The initial contact (IC) service was not examined in this study. Instead, current voice radio procedures for establishing radar contact were implemented. The full data block would appear flashing on the receiving controller's terminal display and an asterisk $\left.{ }^{*}\right)$ would precede the call sign of a data-link-equipped aircraft. The data link was active and available for the controller to uplink the first message. When the controller accepted the handoff, the ghost pilot would state the aircraft call sign, altitude, and current Automatic Terminal Information Service (ATIS) code (e.g., "American one twenty-three with you at one two thousand with information Alpha").

CI and TI Messages. Controllers could select any of the $\mathrm{CI}$ and $\mathrm{TI}$ topics from the menu list presented in Figure 2. The controller depressed [F16] and the alphanumeric key associated with that entry (i.e., 1, 2, 3, A, B, etc.), slewed the trackball until the cursor "E" was overlaid upon the position symbol "E" associated with the desired aircraft, and then depressed the Enter key. During message construction, the alphanumeric keys that were depressed were echoed back in the preview area of the controller's terminal display (e.g., F16 1). After the Enter key on the trackball was depressed, the information in the preview area was erased and replaced by the aircraft call sign, message topic, and the status "SND" in the 


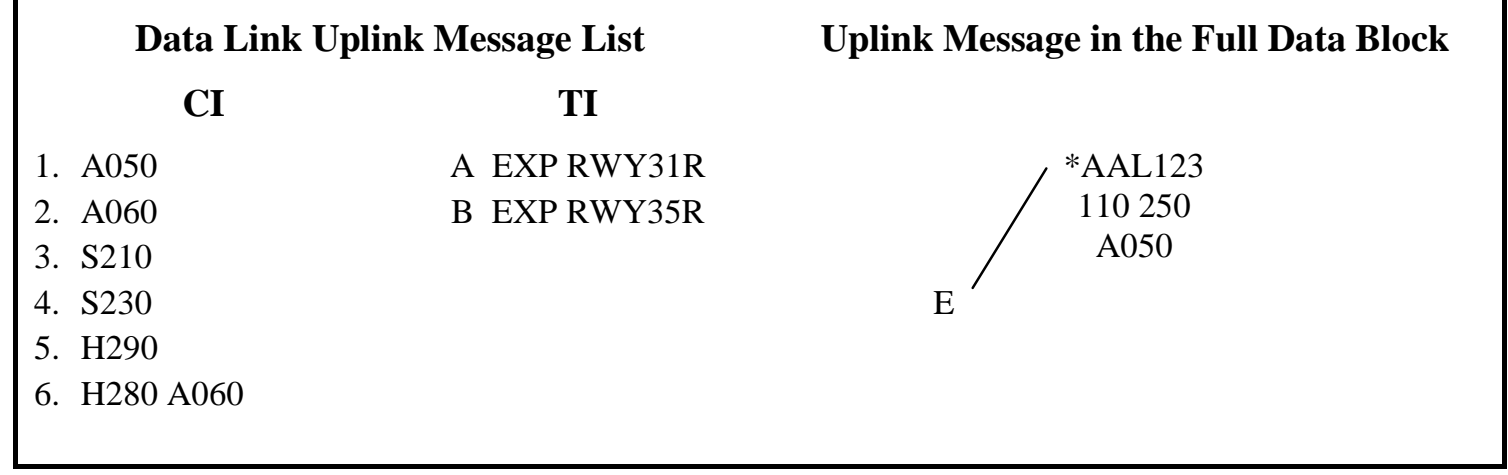

Figure 2. $\mathrm{Cl}$ and $\mathrm{TI}$ Uplink Messages.

status list (e.g., AAL123 A050 SND). The CI message also appeared in the third line of the full data block with the numeric data and an appropriate preceding letter of A, H, or S (e.g., A050).

As soon as the controller sent the uplinked message, it appeared on the ghost pilot's display in the third line of the full data block for the receiving aircraft (e.g., A050). The ghost pilot selected "WILCO" to acknowledge receipt of the uplinked message and, either immediately or after approximately 11 s, sent the downlink to the controller. For the controller's terminal display, "WILCO" remained in the third line of the full data block until the controller closed the transaction. The controller overlaid the cursor and datatag position symbols and then depressed the Enter key on the trackball. This procedure deviated from the original design presented in a MITRE document (1990). In that document, the "WILCO" disappeared from the controller's display after a predetermined timeout parameter. No action on the part of the controller was required. We chose to change this procedure because the controller could be scanning a different area of the controller's terminal display and miss the downlink acknowledgment.

Manual Mode TOC. The sending controller constructed and transmitted the TOC by depressing the [F9] key which resulted in the appearance of the "TC" in the preview area of the controller's terminal display. The controller then slewed the trackball until the sending and receiving controller's position symbols were overlaid upon one another in the data block. When the Enter key on the trackball was depressed, the "TC" disappeared and no further action was required. The ghost pilot did not "WILCO" the TOC, and there was no change to the status list. When the receiving controller accepted responsibility for an aircraft, the sending controller's display was replaced with a radar secondary track, and the sending controller's position symbol was replaced by the receiving controller's position symbol.

The current CPDLC TOC design specification requires a "WILCO" acknowledgment from the pilot for a TOC. It includes the display of a message sent in the data block. It also includes a change in the sending controller's display from a "data link eligibility $\left({ }^{*}\right)$ " to an "active session (+)" indicator meaning that the aircraft is capable of data link communication but the sending sector is no longer eligible to send a message. This feature was not included as part of the transfer of communication in the current study since the sending controller could not communicate with the aircraft by data link once radar transfer was accepted and the TOC was transmitted.

Although the data link services reported here deviated from the current designs being evaluated by FAA for data link services, the fundamental concept is not unique to this simulation study. That is, data link services will be provided by a communications system, that uses digitized signals, as was done here. Likewise, input into that communications system will be performed by controllers who will make entries using a keyboard-input module and trackball, as was done here.

\section{Procedure}

After the required administrative paperwork was completed, each controller received $4 \mathrm{hrs}$ of familiarization training on the simulator. They also were instructed on the procedures for transfer of 
communications (TOC), constructing controller instructions (CI) and terminal information (TI), and transmitting messages using the ARTS IIIA data link interface. During that time, the trainer observed the controllers demonstrating their skill and dexterity with the ABC-style keyboard-input module. The controller completed a 15 -min practice scenario representative of arrival traffic on the sector. Any problems were noted and corrected through additional training or practice.

Following familiarization training, controllers completed a practice scenario to reinforce and increase their data link communication skills. Then controllers completed the first 30-min scenario, provided TLX workload ratings, and received a 15 -min break, and so on until each of the scenarios was completed twice. While providing air traffic services to simulated traffic, controller voice communications were recorded onto digital analog tapes and time stamped. Radar display and ARTS IIIA keyboard and trackball entries were recorded on VHS tapes. At the end of the study, each controller completed a questionnaire and provided a written evaluation and comments related to using data link on the simulated sector.

\section{Experimental Design}

All of the controllers provided air traffic services in a simulation environment supporting dual modes of communications. The temporal characteristics of the ATC simulation environment were examined by manipulating the delay interval of the downlinked responses to ATC messages. Ghost pilots were instructed to provide immediate responses to both data link and voice radio transmissions (immediate condition) or immediate responses to voice radio and delayed responses to data link (mixed condition). All non-data-link-equipped aircraft received immediate responses to their voice radio messages.

Each controller completed the same scenario twice, once with immediate downlink responses and once with downlink responses delayed by approximately $11 \mathrm{~s}$. The order of presentation was counterbalanced. Type of aircraft equipage (data link equipped, nondata link equipped), mode of communications (voice radio, data link) and ghost pilot response type (all immediate, mixed) were the experimental variables of interest. Since the scenario was representative of an actual sample of traffic from the facility, it was congruent with controller expectancies and should not adversely influence workload.

\section{Dependent Measures}

Subjective Workload. Participant ratings, provided on each dimension of the NASA Task Load Index, served as indices of perceived workload. Individual and composite ratings were obtained following each simulation.

Objective Workload. There were 3 measures of objective workload. They were 1) aircraft activity levels, 2) total time on frequency and, 3) hesitation pauses (Eisler 1968). They are enumerated below.

Aircraft Activity Levels. Workload was measured by the number of active aircraft still on frequency when the controller initiated a transmission. An aircraft was counted as being under positive control once it established initial contact with the controller. It was no longer under positive control after the controller completed the 2-stage hand-off procedure: 1) an automated radar hand-off and 2) transfer of communication to the next controller in the sequence. This approach was used to maintain continuity with current transfer of control procedures.

Total Time on Frequency. For messages transmitted by voice-radio, the total time on frequency was measured by placing cursors at the onset and offset of speech, as determined by visual examination of the waveform and by listening to the speech sample. For data link transmissions, total time on frequency was measured as the amount of time that lapsed between the onset of a hand movement to the [F15] or [F16] key on the ARTS IIIA keyboard and when the trackball [ENTER] key was depressed. This was accomplished by viewing the time-stamped audio-video recordings.

Hesitation Pauses. For all participants, withinutterance pause duration and pause frequency were extracted from the audio-videotapes. Some articulatory gestures of speech (e.g., stop consonants, breathing) necessarily result in brief periods of silence ${ }^{2}$. For motor production, both the within-message pause duration and pause frequency were extracted by viewing the videotapes. Pause duration was defined as a

\footnotetext{
${ }^{2}$ Breathing is necessary for fluent speech production. Setting a pause duration of 25 milliseconds (ms) as a lower bound eliminated it as a factor.
} 
lack of a hand movement about the keyboard during message construction. Only transmissions containing pauses exceeding .25s were included. Pause frequency was computed by counting the number of pauses in a transmission.

Communication Performance. Measures of communication performance were associated with the contents of controller messages and message production. Message contents involved the number of aviation topics in a message and non-standard communications. Message production included the adjusted time on frequency (total time on frequency adjusted for hesitation pauses) and message restarts.

Message Production. The adjusted time on frequency and number of restarts were computed for each utterance and data link transmission. The total time that a controller was on frequency consisted of three components: pause duration, message selection/construction, and transmission time. The adjusted time on frequency was derived by subtracting pause duration from total time on frequency.

The number of restarts was defined as the reinitiation of a transmission to an aircraft. This was determined by listening to voice-radio transmissions and counting the number of times the controller told the pilot to "disregard" or reinitiated a message. For data link transmissions, the number of restarts was determined by reviewing the audio-video tapes and counting how often the controller depressed the clear key on the keyboard during message construction.

Message Contents. By parsing messages into message elements, the number of aviation topics in voiceradio and data link messages was determined, tallied, and recorded according to the methods and procedures outlined by Prinzo, Britton, and Hendrix (1995). The number of non-standard communications per message was determined by comparing the phraseology spoken to the required phraseology contained in FAA Order 7110.65 (FAA, 2000).

Initial Contact and Transfer of Control Services. Time is a crucial component of message delivery in maintaining safety. Temporal factors associated with downlinked pilot responses could influence when controllers accept or transfer responsibility for separation assurances between aircraft. An analysis was performed on the controllers' communication and performance to provide initial contact and transfer of control services and data were extracted from videotaped recordings made during each simulation. A template of the aircraft arrival routes containing mile markings from the airport was developed to calculate the aircraft's location along its filed flight plan. The process used to extract temporal and location information pertaining to these services is enumerated below.

Initial Contact Services. For purposes of this study, initial contact services included the acceptance of the radar track and first transmission to a data-linkeligible aircraft. ACCEPT RADAR time was defined as the time lapsed from the moment the controller began to move the trackball onto a flashing target and ended when the trackball Enter key was depressed. ACCEPT RADAR fix was defined as the number of miles the aircraft was from the airport along its arrival route when radar contact occurred.

The INITIAL CALL-UP time to each aircraft was extracted from the verbatim transcripts. It was recorded in minutes and seconds from the onset to offset of the controller's first transmission to a datalink-eligible aircraft. The INITIAL CALL-UP fix was defined as the number of miles the aircraft was from the airport along its arrival route when two-way communications were established and generally occurred when the controller completed the first transmission to the aircraft. Only the amount of time that it took the controller to state the aircraft call sign, call sign plus "Roger," "Contact," or another acknowledgment was included to determine the initial call-up fix.

Transfer of Control Services. The INITIATE TRANSFER OF RADAR TRACK time was measured in minutes: seconds. The moment the controller's hand extended to the keyboard-designation of the receiving controller's position symbol, "J" or " $Z$," to when the hand moved to and depressed the click-button on the slew ball was extracted from videotape. The INITIATE TRANSFER RADAR TRACK fix was measured in miles from aircraft to airport when radar transfer was completed.

The TRANSFER OF COMMUNICATIONS was measured in minutes and seconds from the onset to offset of the final transmission made by the controller transferring communications. Onset time was measured from the moment the sending controller's hand moved to and depressed the [F9] key on the keyboard. Offset time was measured from the moment the sending controller's hand moved to and then depressed the Enter key on the trackball causing the "TC" to disappear from the PVD. The transfer of communication fix was the number of miles the aircraft was from the airport when TOC occurred. 


\section{RESULTS}

The Relationship Between the Temporal Characteristics of the Simulation Environment and Subjective Workload

The temporal characteristics of the simulated ATC environment were examined by manipulating the response delays. Ghost pilots were instructed to provide immediate responses to data-link and voiceradio transmissions (immediate condition) or a combination of immediate responses to voice radio and delayed responses to data link (mixed condition).

The mean and standard deviation (SD) of the subjective ratings for each of the 6-dimensions of the TLX are presented in the main body of Table 3 and the overall rating is presented under the heading "Mean." As shown in Table 3, the average, overall rating was higher for the mixed (49.83) compared to the immediate condition (45.25). Likewise, their ratings on each dimension of the TLX under the mixed condition were higher than under the immediate condition. However, non of these differences were statistically significant.

The Relationship Between the Temporal Characteristics of the Simulation Environment, Objective Workload and Communication Performance

All of the participants communicated with 14 data-link-equipped and 10 non-data-link-equipped aircraft. Incomplete data led to the exclusion of 8 aircraft, of which 3 were data link equipped. Most of these aircraft were in a handoff mode or on final approach at the very beginning or end of the simulation and they served the purpose of filling time as the aircraft of interest entered and departed the scenario.
This left 1,579 of the original 1,952 controllergenerated transmissions in the database. Two separate sets of analyses were performed on each of the dependent measures.

For the first set, the data were arranged according to the type of aircraft equipage and ghost pilotresponse type, while ignoring the mode of communications classification used for information transfer. This allowed for a comparison between ATC operational communications for aircraft with and without a data link capability. During one simulation, all of the aircraft responded immediately to all transmissions (immediate condition). During the other simulation, controllers received immediate oral responses from all of the aircraft to their voice radio communications. Acknowledgments to their data link transmissions from data-link-equipped aircraft were delayed by about 11 s (mixed condition).

For the second set of analyses, the data were rearranged according to the mode of communications used by the controllers for message transfer and ghost pilot-response type, while ignoring the type of aircraft equipage. This allowed for a comparison between mode of communications, independent of aircraft equipage. During each simulation, the temporal characteristics were always immediate for voice radio transmissions (immediate) and either immediate or delayed for data link (mixed).

Type of Aircraft Equipage and Ghost Pilot Response Type (Collapsing on Mode of Communications)

Controller Workload. The results indicated that controller workload was affected by the communications capability onboard the aircraft but not ghost pilot response type. As shown in Table 4, transmissions made

TABLE 3. Mean NASA TLX Ratings Presented by the Temporal Characteristics of the Simulation

NASA TLX Dimensions

Source Mental Physical Temporal Performance* Effort Frustration Mean

Temporal Characteristics

\begin{tabular}{lccccccc} 
Immediate & 45.75 & 45.62 & 45.75 & 42.12 & 43.38 & 48.88 & 45.25 \\
& $(12.24)$ & $(14.48)$ & $(12.08)$ & $(11.42)$ & $(13.94)$ & $(17.84)$ & $(12.13)$ \\
\multirow{2}{*}{ Mixed } & 48.50 & 50.12 & 50.25 & 51.62 & 49.38 & 49.12 & 49.83 \\
& $(15.35)$ & $(13.66)$ & $(11.07)$ & $(12.11)$ & $19.40)$ & $(18.29)$ & $(13.85)$ \\
\hline
\end{tabular}

* A lower value indicates a rating of improved performance 
TABLE 4. Measures of Workload and Communication Performance Presented by Aircraft Equipage and Pilot Response Type (Collapsed over Mode of Communications)

\begin{tabular}{|c|c|c|c|c|c|c|c|c|c|}
\hline & \multicolumn{9}{|c|}{ Objective Measures of Workload and Communication Performance } \\
\hline & $\begin{array}{l}\text { Num } \\
\text { Aircraft }\end{array}$ & $\begin{array}{c}\text { Pause } \\
\text { Duration }\end{array}$ & $\begin{array}{c}\text { Pause } \\
\text { Freq }\end{array}$ & $\begin{array}{l}\text { Total } \\
\text { Time }\end{array}$ & $\begin{array}{c}\text { Adj } \\
\text { Time }\end{array}$ & $\begin{array}{c}\text { Num } \\
\text { Restarts }\end{array}$ & $\begin{array}{l}\text { Num } \\
\text { Topics }\end{array}$ & $\begin{array}{l}\text { NSC per } \\
\text { Message }\end{array}$ & $\begin{array}{c}\text { Num } \\
\text { Syllables }\end{array}$ \\
\hline \multicolumn{10}{|l|}{ Aircraft Equipage } \\
\hline Data Link & $\begin{array}{c}6.22 \\
(1.01)\end{array}$ & $\begin{array}{l}.39 * \\
(.47)\end{array}$ & $\begin{array}{l}.09 \\
(.07)\end{array}$ & $\begin{array}{l}3.49 * \\
(.69)\end{array}$ & $\begin{array}{l}3.10 * \\
(.37)\end{array}$ & $\begin{array}{l}.04 * \\
(.03)\end{array}$ & $\begin{array}{l}2.35^{*} \\
(.14)\end{array}$ & $\begin{array}{l}.30 * \\
(.30)\end{array}$ & $\begin{array}{l}18.10 \\
(1.03)\end{array}$ \\
\hline Non-Data Link & $\begin{array}{c}6.33 \\
(1.04)\end{array}$ & $\begin{array}{l}.03 \\
(.03)\end{array}$ & $\begin{array}{l}.05 \\
(.05)\end{array}$ & $\begin{array}{l}2.63 \\
(.27)\end{array}$ & $\begin{array}{l}2.60 \\
(.27)\end{array}$ & $\begin{array}{l}.02 \\
(.03)\end{array}$ & $\begin{array}{l}2.53 \\
(.12)\end{array}$ & $\begin{array}{l}.77 \\
(.23)\end{array}$ & $\begin{array}{c}19.02 \\
(19.32)\end{array}$ \\
\hline \multicolumn{10}{|l|}{ Ghost Pilot Response Type } \\
\hline Immediate & $\begin{array}{l}6.19 \\
(.72)\end{array}$ & $\begin{array}{l}.14 \\
(.20)\end{array}$ & $\begin{array}{l}.08 \\
(.06)\end{array}$ & $\begin{array}{l}2.98 \\
(.54)\end{array}$ & $\begin{array}{l}2.84 \\
(.40)\end{array}$ & $\begin{array}{l}.02 \\
(.02)\end{array}$ & $\begin{array}{c}2.46^{*} \\
(.18)\end{array}$ & $\begin{array}{l}.58 \\
(.38)\end{array}$ & $\begin{array}{l}18.76 \\
(1.38)\end{array}$ \\
\hline Mixed & $\begin{array}{c}6.36 \\
(1.26)\end{array}$ & $\begin{array}{l}.28 \\
(.49)\end{array}$ & $\begin{array}{l}.06 \\
(.06)\end{array}$ & $\begin{array}{l}3.14 \\
(.80)\end{array}$ & $\begin{array}{l}2.86 \\
(.43)\end{array}$ & $\begin{array}{l}.04 \\
(.04)\end{array}$ & $\begin{array}{l}2.42 \\
(.13)\end{array}$ & $\begin{array}{l}.49 \\
(.33)\end{array}$ & $\begin{array}{l}18.36 \\
(1.13)\end{array}$ \\
\hline \multicolumn{10}{|c|}{ Aircraft Equipage by Pilot Response Type } \\
\hline Data Link - Immediate & $\begin{array}{l}6.15 \\
(.66)\end{array}$ & $\begin{array}{l}.24 \\
(.24)\end{array}$ & $\begin{array}{l}.08 \\
(.07)\end{array}$ & $\begin{array}{l}3.31 \\
(.55)\end{array}$ & $\begin{array}{l}3.07 \\
(.40)\end{array}$ & $\begin{array}{l}.03 \\
(.02)\end{array}$ & $\begin{array}{l}2.37 \\
(.16)\end{array}$ & $\begin{array}{l}.34 \\
(.32)\end{array}$ & $\begin{array}{l}18.36 \\
(1.15)\end{array}$ \\
\hline Non-Data Link - Immediate & $\begin{array}{l}6.23 \\
(.83)\end{array}$ & $\begin{array}{l}.03 \\
(.03)\end{array}$ & $\begin{array}{l}.07 \\
(.05)\end{array}$ & $\begin{array}{l}2.64 \\
(.27)\end{array}$ & $\begin{array}{l}2.61 \\
(.26)\end{array}$ & $\begin{array}{l}.01 \\
(.03)\end{array}$ & $\begin{array}{l}2.56 \\
(.14)\end{array}$ & $\begin{array}{c}.82 \\
(.26)\end{array}$ & $\begin{array}{l}19.17 \\
(1.55)\end{array}$ \\
\hline Data Link - Mixed & $\begin{array}{c}6.28 \\
(1.32)\end{array}$ & $\begin{array}{l}.54 \\
(.61)\end{array}$ & $\begin{array}{l}.09 \\
(.07)\end{array}$ & $\begin{array}{l}3.67 \\
(.80)\end{array}$ & $\begin{array}{l}3.13 \\
(.37)\end{array}$ & $.059 .04)$ & $\begin{array}{l}2.33 \\
(.11)\end{array}$ & $\begin{array}{l}.26 \\
(.28)\end{array}$ & $\begin{array}{l}17.84 \\
(0.90)\end{array}$ \\
\hline Non-Data Link - Mixed & $\begin{array}{c}6.44 \\
(1.28)\end{array}$ & $\begin{array}{c}.02 \\
(.03)\end{array}$ & $\begin{array}{c}.02 \\
(.03)\end{array}$ & $\begin{array}{l}2.62 \\
(.32)\end{array}$ & $\begin{array}{l}2.60 \\
(.30)\end{array}$ & $\begin{array}{l}.02 \\
(.03)\end{array}$ & $\begin{array}{l}2.50 \\
(.10)\end{array}$ & $\begin{array}{l}.72 \\
(.18)\end{array}$ & $\begin{array}{l}18.87 \\
(1.14)\end{array}$ \\
\hline
\end{tabular}

*Statistically significant, $\mathrm{p} \leq .05$.

to data-link-equipped aircraft took longer to complete (total time) than transmissions to non-data-linkequipped aircraft, $\mathrm{F}(1,7)=60.06, \mathrm{p}<.05$. Likewise, transmissions made to data-link-equipped aircraft contained longer pauses than those made to non-data-linkequipped aircraft, $\mathrm{F}(1,7)=9.64, \mathrm{p}<.05$. The difference observed between data link and non-data-link-equipped aircraft for pause frequency was not significant, $\mathrm{F}(1,7)$ $=2.31, \mathrm{p}>.05$.

Communication Performance. As in the previous Prinzo study (1998), even when hesitation pauses are removed from the controllers' transmissions, they still spent more time on frequency communicating with data-link-equipped aircraft, $F(1,7)=29.17$, $\mathrm{p}<.05$. In addition, messages transmitted to datalink-equipped aircraft were more accurate, $F(1,7)=$ 69.51, $\mathrm{p}<.05$, and contained fewer aviation topics, $\mathrm{F}(1,7)=20.27, \mathrm{p}<.05$. Controllers also transmitted more aviation topics when ghost pilot responses were immediate, $F(1,7)=9.19, \mathrm{p}<.05$. Finally, controllers also restarted transmissions to data-link-equipped aircraft more often than to non-data-link-equipped aircraft, $F(1,7)=19.16, \mathrm{p}<.05$.

Mode of Communications and Pilot Response Type (Collapsing on Aircraft Equipage)

Controller Workload. As shown in Table 5, the mode of communications used by controllers influenced workload but ghost pilot response type did not. That is, when controllers used data link, their transmissions took nearly $2 \mathrm{~s}$ longer to complete than messages sent by voice (mean total time $\mathrm{DL}=4.39 \mathrm{~s}$, $\mathrm{V}=2.40 \mathrm{~s}), \mathrm{F}(1,7)=35.93, \mathrm{p}<.05$. Also, data link messages contained longer pauses (i.e., pause duration) than messages initiated by voice radio, $\mathrm{F}(1,7)$ $=7.89, \mathrm{p}<.05$. 
TABLE 5. Measures of Workload and Communication Performance Presented by Mode of Communications and Ghost Pilot Response Type (Collapsed over Aircraft Equipage)

\begin{tabular}{|c|c|c|c|c|c|c|c|c|c|}
\hline \multirow[b]{2}{*}{ Source } & \multicolumn{9}{|c|}{ Measures of Workload and Communication Performance } \\
\hline & $\begin{array}{c}\text { Num } \\
\text { Aircraft }\end{array}$ & $\begin{array}{c}\text { Pause } \\
\text { Duration }\end{array}$ & $\begin{array}{c}\text { Pause } \\
\text { Freq }\end{array}$ & $\begin{array}{l}\text { Total } \\
\text { Time }\end{array}$ & $\begin{array}{c}\text { Adj } \\
\text { Time }\end{array}$ & $\begin{array}{c}\text { Num } \\
\text { Restarts }\end{array}$ & $\begin{array}{c}\text { Num } \\
\text { Topics }\end{array}$ & $\begin{array}{l}\text { NSC per } \\
\text { Message }\end{array}$ & $\begin{array}{c}\text { Num } \\
\text { Syllables }\end{array}$ \\
\hline \multicolumn{10}{|c|}{ Mode of Communications } \\
\hline Data Link & $\begin{array}{l}6.23 \\
(.98)\end{array}$ & $\begin{array}{l}.63^{*} \\
(.79)\end{array}$ & $\begin{array}{l}.12 \\
(.11)\end{array}$ & $\begin{array}{l}4.39^{*} \\
(1.01)\end{array}$ & $\begin{array}{l}3.77^{*} \\
(.46)\end{array}$ & $\begin{array}{c}.08^{*} \\
(.06)\end{array}$ & $\begin{array}{c}2.13 * \\
(.01)\end{array}$ & $\begin{array}{l}0.00^{*} \\
(.00)\end{array}$ & $\begin{array}{l}18.44 \\
(.94)\end{array}$ \\
\hline Voice Radio & $\begin{array}{c}6.27 \\
(1.10)\end{array}$ & $\begin{array}{l}.02 \\
(.02)\end{array}$ & $.049 .04)$ & $\begin{array}{l}2.40 \\
(.23)\end{array}$ & $\begin{array}{l}2.38 \\
(.22)\end{array}$ & $\begin{array}{l}0.00 \\
(.00)\end{array}$ & $\begin{array}{l}2.60 \\
(.10)\end{array}$ & $\begin{array}{c}.74 \\
(.34)\end{array}$ & $\begin{array}{l}18.34 \\
(1.13)\end{array}$ \\
\hline \multicolumn{10}{|c|}{ Ghost Pilot Response Type } \\
\hline Immediate & $\begin{array}{l}6.18 \\
(.70)\end{array}$ & $\begin{array}{l}.21 \\
(.32)\end{array}$ & $\begin{array}{l}.08 \\
(.07)\end{array}$ & $\begin{array}{c}3.30 \\
(1.07)\end{array}$ & $\begin{array}{l}3.09 \\
(.82)\end{array}$ & $\begin{array}{c}.03 \\
(.040)\end{array}$ & $\begin{array}{l}2.38 \\
(.28)\end{array}$ & $\begin{array}{l}.39 \\
(.48)\end{array}$ & $\begin{array}{l}18.64 * \\
(1.09)\end{array}$ \\
\hline Mixed & $\begin{array}{c}6.31 \\
(1.29)\end{array}$ & $\begin{array}{l}.43 \\
(.83)\end{array}$ & $\begin{array}{l}.08 \\
(.10)\end{array}$ & $\begin{array}{c}3.49 \\
(1.43)\end{array}$ & $\begin{array}{l}3.05 \\
(.79)\end{array}$ & $\begin{array}{l}.05 \\
(.07)\end{array}$ & $\begin{array}{l}2.36 \\
(.26)\end{array}$ & $\begin{array}{l}.34 \\
(.42)\end{array}$ & $\begin{array}{l}18.19 \\
(.94)\end{array}$ \\
\hline \multicolumn{10}{|c|}{ Mode of Communications by Ghost Pilot Response Type } \\
\hline Data Link - Immediate & $\begin{array}{l}6.20 \\
(.66)\end{array}$ & $\begin{array}{l}.40 \\
(.38)\end{array}$ & $\begin{array}{l}.09 \\
(.10)\end{array}$ & $\begin{array}{l}4.16 \\
(.83)\end{array}$ & $\begin{array}{l}3.78 \\
(.58)\end{array}$ & $\begin{array}{l}.06 \\
(.04)\end{array}$ & $\begin{array}{l}2.13 \\
(.13)\end{array}$ & $\begin{array}{l}0.00 \\
(.00)\end{array}$ & $\begin{array}{l}18.70 \\
(1.08)\end{array}$ \\
\hline Voice Radio - Immediate & $\begin{array}{l}6.16 \\
(.78)\end{array}$ & $\begin{array}{l}.03 \\
(.02)\end{array}$ & $\begin{array}{l}.06 \\
(.05)\end{array}$ & $\begin{array}{l}2.43 \\
(.19)\end{array}$ & $\begin{array}{l}2.40 \\
(.18)\end{array}$ & $\begin{array}{l}0.00 \\
(.00)\end{array}$ & $\begin{array}{l}2.62 \\
(.09)\end{array}$ & $\begin{array}{l}.78 \\
(.37)\end{array}$ & $\begin{array}{l}18.59 \\
(1.17)\end{array}$ \\
\hline Data Link - Mixed & $\begin{array}{c}6.25 \\
(1.27)\end{array}$ & $\begin{array}{c}.86 \\
(1.03)\end{array}$ & $\begin{array}{l}.14 \\
(.12)\end{array}$ & $\begin{array}{c}4.62 \\
(1.17)\end{array}$ & $\begin{array}{l}3.76 \\
(.35)\end{array}$ & $\begin{array}{l}.09 \\
(.07)\end{array}$ & $\begin{array}{l}2.13 \\
(.11)\end{array}$ & $\begin{array}{l}0.00 \\
(.00)\end{array}$ & $\begin{array}{l}18.17 \\
(.76)\end{array}$ \\
\hline Voice Radio - Mixed & $\begin{array}{c}6.38 \\
(1.40)\end{array}$ & $\begin{array}{c}.01 \\
(.01)\end{array}$ & $\begin{array}{c}.02 \\
(.02)\end{array}$ & $\begin{array}{l}2.36 \\
(.27)\end{array}$ & $\begin{array}{l}2.35 \\
(.27)\end{array}$ & $\begin{array}{l}0.00 \\
(.00)\end{array}$ & $\begin{array}{l}2.59 \\
(.11)\end{array}$ & $\begin{array}{c}.69 \\
(.32)\end{array}$ & $\begin{array}{l}18.21 \\
(1.14)\end{array}$ \\
\hline
\end{tabular}

*Statistically significant, $\mathrm{p} \leq .05$.

Communication Performance. As expected, controllers spent more time on frequency even when pauses were removed from their data link transmissions (i.e., adjusted for pause duration), $\mathrm{F}(1,7)=$ $190.27, \mathrm{p}<.05$. Although data link, rather than voice messages were restarted more often $\mathrm{F}(1,7)=19.81$, $\mathrm{p}<.05$, the data link messages were more accurate, $\mathrm{F}(1,7)=37.13, \mathrm{p}<.05$, and contained fewer aviation topics than those transmitted by voice radio, $\mathrm{F}(1,7)$ $=181.45, \mathrm{p}<.05$. This finding was replicated on 1,430 of the original 1,954 transmissions - transmissions devoid of common salutations, courtesies, or both. Transmissions that involved initial contact also were excluded since they were performed using voice radio. Once again, more topics were transmitted by voice radio $($ Mean $=2.21 \mathrm{SD}=.14)$ than data link $($ Mean $=2.16 \mathrm{SD}=.11), \mathrm{t}(1,7)=-3.01, \mathrm{p}<.05$. When aircraft, regardless of communications equipage, responded immediately, controllers' transmissions were notably longer (number of syllables), $\mathrm{F}(1,7)=$ $5.93, \mathrm{p}<.05$, although not more informative (number of topics) or requiring longer to transmit.

The Relationship Between the Temporal Characteristics of Downlinked Ghost Pilot Response Type and Initial Contact and Transfer of Control Performance

Based on the previously reported studies, it was anticipated that the amount of time controllers allotted for initial contact and transfer of control services was a function of the temporal aspects of communications system. Therefore, directional, paired t-tests were performed for only data-link-equipped aircraft that completed initial call-up, initiate transfer radar track, and transfer of communication subtasks. There were 206 controller transmissions made to data-linkeligible aircraft ( 70 voice-radio and 136 data link). The 
TABLE 6. Ghost Pilot Response Type, Air Traffic Service, and Mode of Communications Presented by Distance from the Airport and Time to Complete Each Subtask

Distance and Time to Complete ATC Subtasks

Distance (in miles) Time (in seconds)

$\begin{array}{llll}\text { Source } & \text { Radar } & \text { Communications } & \text { Radar }\end{array}$

Initial Contact Services

Ghost Pilot Response Type

$\begin{array}{lllll}\text { Immediate } & 64.26(1.23) & 62.60(1.01) & 3.16(0.45) & 1.82(0.31) \\ \text { Delayed } & 64.46(1.32) & 62.73(1.35) & 3.98(1.43) & 1.82(0.33)\end{array}$

Transfer of Control Services

Ghost Pilot Response Type

\begin{tabular}{|c|c|c|c|c|}
\hline Immediate & $43.63(12.70)$ & $33.50(2.37)$ & $2.72(0.54)$ & $2.64(0.39)^{*}$ \\
\hline Delayed & $44.15(9.64)$ & $33.42(1.74)$ & $2.59(.30)$ & $3.85(1.14)$ \\
\hline \multicolumn{5}{|c|}{ Mode of Communications } \\
\hline Data Link & $40.41(11.87)$ & $33.91(2.60)$ & $3.09(0.72)$ & $3.29(0.38)$ \\
\hline Voice Radio & 42.91 ( 9.17) & $34.32(1.84)$ & $2.68(0.43)$ & $2.65(0.19)$ \\
\hline
\end{tabular}

*Statistically significant, $\mathrm{p} \leq .05$.

mean and SD time (to perform each subtask and the aircraft's distance along its arrival route to the airport are presented in Table 6.

As predicted for the Initial Contact Services, there were no differences in where an aircraft was as it approached the sector or how long controllers took to accept radar contact or establish communications since the procedure associated with each subtask was retained. In addition for the Transfer of Control Service, it is not surprising that no difference was observed for the transfer of radar track subtask since the receiving controller accepted the radar track as soon as it appeared flashing on his radar display. There was, however, a significant difference resulting from the temporal characteristic of the downlinked response - when responses were delayed, controllers took an additional $1.2 \mathrm{~s}$ to complete the transfer of communications subtask, $\mathrm{t}(7)=-2.44, \mathrm{p}<.05$. A final analysis revealed that the mode of communications that controllers selected did not influence the distance or time measures of transfer of radar track and communications subtask performance.

As mentioned previously, controllers could complete the transfer of control services transfer of communications subtask by voice radio or data link using the manual mode TOC. When the analyses performed on the temporal characteristics of the ghost pilot responses and mode of communications are taken together, the data revealed that temporal demands - not mode of communications - significantly influenced controller performance of the transfer of communications subtask.

\section{DISCUSSION}

Operational communication tasks, whether performed by pilots or by air traffic controllers, take time to complete. As data link becomes fully integrated into the air traffic control system and CPDLC is transitioned into the operational environment, controllers will have the flexibility to determine which air traffic services are provided by voice radio and by data link. It stands to reason that the workload experienced by controllers will change as communication become less verbally- (listen, speak) and more visually- (eye, hand) driven. Along the same lines, it would seem that changes in the temporal aspects of the communications system would influence the performance of operational communication tasks by controllers. 
In this simulation study, the temporal aspects of the communications environment was manipulated by having controllers experience either no pilot downlink delay or a delay of approximately $11 \mathrm{~s}$. Pilot delays did not seem to unfavorably influence controllers' perceptions of workload, although they generally felt that their performance was somewhat affected. Unlike the Prinzo study (1998) that reported a significant increase in the frequency of pauses in the mixed modality environment, it was not a significant factor in this study because all communications occurred in a mixed environment. Interestingly, the same trend appeared for more frequent pauses when communications involved aircraft equipped with voice radio + data link than aircraft equipped for voice radio.

The only evidence of changes in workload came from the objective measures of total time on frequency and duration of pauses. Specifically, transmissions to data-link-equipped aircraft took .86s longer to complete than those to non-data-linkequipped aircraft (DL aircraft $=3.49 \mathrm{~s}$, NDL aircraft $=2.63 \mathrm{~s}$ ). The longer transmission times to data-linkequipped aircraft were the result of the mode of communications selected by the controller. In particular, when controllers sent messages over a data link, they took nearly $2 \mathrm{~s}$ longer to complete those transmissions than messages sent by voice radio (DL message $=4.39 \mathrm{~s}, \mathrm{~V}$ message $=2.40 \mathrm{~s}$ )

Why did controllers' data link transmissions take longer? Part of the reason may lie in the observation that, of the 114 transmissions containing pauses, over $60 \%$ involved data link $(\mathrm{DL}=73, \mathrm{~V}=41)$. The longer pauses in these data link messages suggest that controllers had more time available for strategic processes and planning activities (Ericsson \& Simon, 1980). Prinzo et al. (1998) suggest that the longer pauses made by controllers in an earlier simulation study could reflect cognitive activity associated with strategizing during message construction. Just as light traffic, coupled with expertise, may have afforded controllers in the earlier study more time to think, providing controllers in this study with a multi-modal communications system may have alleviated the communications bottleneck imposed by one-user-at-a-time communications.
An examination of the controller data link messages revealed transmissions with pauses greater than 20 s involved either a transfer of communications $(60 \%)$ or an instruction to descend to a lower altitude (40\%). Generally, controllers constructed these messages while an aircraft was approaching a sector boundary or transition point. While waiting, they had the opportunity to send a voice message to another non-data-link-equipped aircraft. In fact, at the controllers discretion, over 100 pairs of transmissions (i.e., $11 \%$ of the transmissions) involved parallel performance of operational communications tasks. It was discovered that, if the first message gave advance runway information (31\%) or an instruction $(37 \%)$, the controller was simultaneously establishing radar contact $(44 \%)$ or transferring communications $(25 \%)$ with another aircraft. Temporal factors did not seem to be a factor in the development of this efficiency strategy. It appears, then, that the longer pauses may have resulted from controllers selecting/ constructing messages best suited for the current operational task, thereby providing communications in parallel, or both. Using a multi-modal, simultaneous communications system provided these controllers with the capability for off-loading routine, non-time critical, operational tasks to data link, while simultaneously performing verbal communication tasks.

Communication performance also was influenced by mode of communications. Controllers had the option of sending single or multiple topic messages either by voice (e.g., descend to and maintain five thousand, turn right heading two eight zero, descend and maintain six thousand) or data link (e.g., A050, H280 A060). When messages were transmitted to aircraft that were not data link equipped, they often contained common salutations and courtesies typical of social situations. Although such commonplace, non-standard communications are not part of the required phraseology contained in FAA Order 7110.65 nor are they included in the CPDLC message set ${ }^{3}$. The presence of these non-standard communications also added to the length of voice radio transmissions. Another analysis was performed on a restricted set of messages devoid of common salutations, courtesies, or involved in initial contact services. The results of that analysis replicated the original finding and

\footnotetext{
${ }^{3}$ See US DOT FAA Specifications for Controller-Pilot Data Link Communications Build 1A, Appendix A.
} 
supported the conclusion that mode of communications affected message length, but the temporal aspects of the mode of communications did not.

The absence of these non-standard communications in data link messages also helps to explain why messages that were sent to aircraft equipped with data link were more precise and shorter. First, data link topics were preformatted, thus making them less error-prone. Second, the data link message set does not include any pleasantries or salutations. Third, more of the messages that were transmitted to datalink-equipped aircraft were sent by data link than by voice radio. Finally, controllers were not provided with an option or opportunity to construct or append "freetext" as part of their uplink messages. Communication performance also was influenced by the temporal aspects of the communications environment. When working dynamic air traffic, where all the aircraft responded immediately, regardless of equipage, controllers' messages were notably longer (number of syllables) but not necessarily more informative (number of topics) nor did they take longer to transmit. When aircraft response time varied, as they did in the mixed condition, (immediate, delayed by $11 \mathrm{~s}$ ) controllers took an additional 1.2s to complete the transfer of communications subtask. And it is not surprising that neither aircraft distance from the airport nor the amount of time taken to complete the transfer of radar subtask were affected by the 11 s delay. Since the delays associated with data link were independent of radar subtasks, controllers were not compelled to develop compensatory strategies because none were needed. It is also possible that delay had no effect because the receiving controller accepted the radar handoff as soon as the data tag began flashing. Future studies may be needed to explore the automatic mode for the transfer of communications subtask. When operating in the automatic mode, the CPDLC system will send the TOC uplink message after hand-off acceptance of the track ${ }^{4}$.

In summary, the primary finding of this study was that controllers took longer to formulate and transmit messages over a data link-communications system, but their messages were more accurate and contained fewer message elements. It would seem that controller access to and the availability of different modes of communication clearly improved the efficiency of ATC/pilot communications. Prior to data link, operational tasks were performed successively. When data link communications becomes part of the air traffic control environment controllers will have the option of performing tasks sequentially or in parallel using either voice radio or CPDLC. As indicated by the communications data, the longer latencies associated with data link messages often resulted from deliberate actions on the part of the controllers. The longer latencies did not result in a loss of efficiency but reflected innovations on the part of the controllers to optimize their performance. By placing data link messages in a pending status controllers could participate in concurrent communications with other non-data-link-equipped aircraft. This benefit provided controllers with added flexibility and clearly enabled them to decide which modality was best suited for each operational communications task.

\section{REFERENCES}

Bower, G. H., \& Clapper, J. P. (1989). Experimental methods in cognitive science. In M. P. Posner (Ed.), Foundations of Cognitive Science (p. 245300). Cambridge: MIT Press.

Carroll, D. W. (1986). Psychology of Language. Monterey CA: Brooks/Cole Publishing Co.

Data Link Benefits Study Team (1995). User benefits of two-way data link communications: Aircraft delay and flight efficiency in congested en route airspace. Final Report, DOT/FAA/CT-95-4, Federal Aviation Administration Technical Center. (pp 126).

Data Link Benefits Study Team (1996). Benefits of controller-pilot data link ATC communications in terminal airspace. Final Report. DOT/FAA/CT96-3. Federal Aviation Administration Technical Center. (pp 137).

Eisler, F. G. (1968). Psycholinguistics: Experiments in spontaneous speech. London: Academic Press.

Ericksson, K. A., \& Simon, H. A. (1980). Verbal reports as data. Psychological Review, 87, 215-51.

\footnotetext{
${ }^{4}$ See US DOT FAA Specifications for Controller-Pilot Data Link Communications Build 1A, Section 3.2.2.2.1.1. Radio Frequency Transfer.
} 
Federal Aviation Administration (1991). National airspace system ARTS IIIA operations and procedures student reference manual. Fifth Edition, Third Printing. Oklahoma City: Federal Aviation Administration Academy Air Traffic Branch.

Federal Aviation Administration (1995). Operational Requirements Document for the Aeronautical Data Link System. Washington, DC: Federal Aviation Administration Advanced Automation Program.

Federal Aviation Administration (1997). Program plan for aeronautical data link systems. Washington, DC: Federal Aviation Administration Advanced Automation Program.

Federal Aviation Administration (1998a). Initial Requirements Document for Controller Pilot Data Link Communications (CPDLC) Service. Washington, DC: Federal Aviation Administration Air Traffic System Requirements Service.

Federal Aviation Administration Specification (1998b). Controller Pilot Data Link Communications Build1A (CPDLC-1A) Service. FAA-E 2930. Washington, DC: Federal Aviation Administration.

Federal Aviation Administration (2000). FAA Order 7110.65, Air Traffic Control. Federal Aviation Administration. Washington, DC: U.S. Government Printing Office.

Groce, J. L., \& Boucek, G. P. (1987). Air transport crew tasking in an ATC data link environment. (SAE Technical Paper 87164). Warrendale, PA: Society of Automotive Engineers Inc.

Hart, S. G., \& Staveland, L. E. (1988). Development of NASA-TLX (Task Load Index): Results of empirical and theoretical research. In P. A. Hancock $\&$ N. Meshkati (Eds.), Human Mental Workload (p. 239-50). Amsterdam: North-Holland.

Knox, C. E., \& Scanlon, C. H. (1991). Flight tests with a data link used for air traffic control information exchange. (NASA Technical Paper 3135.) Hampton, VA: National Aeronautics and Space Administration Langley Research Center. (p. 34).

Kerns, K. (1991). Data link communication between controllers and pilots: A review and synthesis of the simulation literature. The International Journal of Aviation Psychology, 1(3), 181-204.
Logsdon, E. W., Infield, S. E., Lozito, S. Mackintosh, M., McGann, A., \& Possolo, A. (April, 1995). Cockpit data link technology and flight crew communication procedures. In R. S. Jensen (Ed.), Proceedings of the Eighth International Symposium of Aviation Psychology, Volume 1 (p. 324-9). Columbus, Ohio: The Ohio State University.

McGann, A., Morrow, D., Rodvold, M. and Mackintosh, M. (1998). Mixed-media communication on the flight deck: A comparison of voice, data link, and mixed ATC environments. International Journal of Aviation Psychology, 8, 137-156.

Porterfield, D. H. (1997). Evaluating controller communication time as a measure of workload. International Journal of Aviation Psychology, 7, 171-82.

Prinzo, O. V. (November, 1998). How controller-topilot data link communications might affect feeder controller workload in a terminal option. Paper presented at the $17^{\text {th }}$ Digital Avionics Systems Conference sponsored by IEEE/AIAA, Bellevue, WA.

Prinzo, O. V., Britton, T. W., and Hendrix, A. (1995). Development of a coding form for approach controll pilot voice communications. Washington, DC: FAA Office of Aviation Medicine Report, DOT/FAA/ AM-95/15. Available from: National Technical Information Service, Springfield, VA 22161; ordering no. ADA295009. (p. 34).

Prinzo, O. V., Lieberman, P., and Pickett, E. (1998). An acoustic analysis of ATC communication. Washington, DC: Federal Aviation Administration, Office of Aviation Medicine Technical Report DOT/FAA/AM-98/20. (p. 27)

Ruitenberg, B. (1998) The human factors of CNS/ ATN. The Controller, 7, 25-7.

Society of Automotive Engineers. (1996) Human Engineering Recommendations for Data Link Systems. Warrensdale: SAE Aerospace Recommended Practices (ARP $4791 \mathrm{~A}$ ).

Stricht, T. G. and Hall, J. H. (1984). Listening and reading. In P. D. Pearson (Ed.), Handbook of Reading Research (p. 293-317). New York: Longman Inc. 
The MITRE Corporation (1990). Study of pilot readback, controller hearback, communication errors. (Number WP-90W00348). McLean, VA.

Talotta, N. J., Shingledecker, C., \& Reynolds, M. (1990). Operational evaluation of initial data link en route services, Volume I (Report No. DOT/ FAA/CT-90/1, I). Washington, DC: U.S. Department of Transportation, Federal Aviation Administration.
Waller, M., \& Lohr, G. (1989). A piloted simulation study of data link ATC message exchange. (NASA Technical Paper 2859.) Hampton, VA: National Aeronautics and Space Administration Langley Research Center. (p. 38). 